\title{
Solar Damage To the Solitary Ascidian, Corella Inflata
}

Brian L. Bingham

Western Washington University, brian.bingham@wwu.edu

Adam M. Reitzel

University of Florida

Follow this and additional works at: https://cedar.wwu.edu/esci_facpubs

Part of the Environmental Sciences Commons

\section{Recommended Citation}

Bingham, Brian L. and Reitzel, Adam M., "Solar Damage To the Solitary Ascidian, Corella Inflata" (2000). Environmental Sciences Faculty and Staff Publications. 9.

https://cedar.wwu.edu/esci_facpubs/9 


\title{
Solar damage to the solitary ascidian, Corella inflata
}

\author{
B.L. Bingham* and A.M. Reitzel \\ *Huxley College of Environmental Studies, Western Washington University, Bellingham, Washington 98225, USA. \\ E-mail: bingham@cc.wwu.edu. Department of Zoology, University of Florida, Gainsville, Florida 32611, USA
}

\begin{abstract}
The ascidian Corella inflata (Chordata, Ascidiacea) is common in many areas of Puget Sound, Washington, USA. However, it occurs only in habitats where it is protected from direct sunlight. Previous experiments with artificial lights showed that UV irradiation kills all life stages of this animal. The effects of natural sunlight exposure (measuring survival of adults, juveniles, larvae, and embryos) were compared. We partitioned the light spectrum to separate the effects of UVB, UVA, and visible light (PAR). Natural sunlight severely damaged C. inflata. Adults and juveniles died after 2-5d. Exposed embryos failed to develop normally and larvae did not settle. As expected, UVB had significant effects, but pronounced effects were also seen when the animals were exposed to longer wavelengths alone (UVA and PAR). Thus, the distribution of C. inflata may be determined largely by exposure to light. Understanding the basic ecology of this species requires consideration of its vulnerability to sunlight damage and the effects of UVB, UVA, and PAR.
\end{abstract}

\section{INTRODUCTION}

Research over the past two decades has clearly demonstrated the harmful effects of UV radiation on plants and animals in terrestrial, freshwater, and marine environments (e.g. Jokiel, 1980; Bornman \& Teramura, 1993; Karentz et al., 1994; Williamson, 1996). The lethal effects of UV are generally attributed to DNA damage. However, damage to other biological molecules (e.g. RNA, enzymes, proteins) can indirectly harm organisms, leading to slower growth, reduced fecundity, and increased mortality (Karentz, 1994; Buma et al., 1995). Such 'organismal level' effects may have population or community-wide consequences (e.g. Dey et al., 1988; Zellmer, 1998).

The effects of UV radiation are strongly wavelength dependent and vary significantly within a few nanometres. In general, shorter wavelengths are very damaging. Longer wavelengths can be harmful or beneficial. A complete understanding of UV effects requires an action spectrum for each species. Such spectra measure the damage caused by UV at individual wavelengths and permit the calculation of biological weighting functions. Few researchers have acquired such information. In fact, even the relative importance of broadband UVB and UVA is unknown for most species.

Bingham \& Reyns (1999) studied the effects of UV radiation on the solitary ascidian, Corella inflata (Huntsman). This sessile marine invertebrate is abundant in Puget Sound, Washington, USA (see Lambert, 1968; Lambert et al., 1981), where it occurs primarily on floating docks. Adults have a thin, transparent tunic in contrast to the thicker, more opaque tunics of most solitary ascidians. Bingham \& Reyns (1999) found that this species lives in locations where it is protected from direct sunlight and hypothesized that the distribution was related to UV sensitivity. Using artificial UV sources in the laboratory, they tested the effects of UV exposure and found that UV kills all life history stages of $C$. inflata.
The susceptibility of $C$. inflata to UV damage is related to their transparency, the absence of UV-shielding compounds (Kobayashi et al., 1981; Karentz et al., 1991; Dionisio-Sese et al., 1997) and their inability to move once the free-swimming larva has settled. They appear to be completely vulnerable to light damage and Bingham \& Reyns (1999) suggested that UV damage sets limits to their distribution.

The extrapolation of laboratory UV results to the field can be problematic (Björn \& Teramura, 1993). Since different wavelengths have different biological effects, laboratory light sources must closely mimic natural sunlight to determine true effects. In practice, this is extremely difficult to achieve.

In the study by Bingham \& Reyns (1999) the integrated UV intensity of the laboratory light sources was close to the maximum ambient UV intensity. However, the spectrum was weighted to the shorter, more damaging wavelengths and the experiments may have exaggerated UV damage. Equally important, the laboratory UVA and visible light intensities were significantly lower than ambient. This may have prevented DNA repair mechanisms from functioning properly (Mitchell \& Karentz, 1993; Karentz, 1994).

The purpose of this study was to test the effects of natural sunlight on C. inflata and determine whether, in its natural habitat, it could be affected by light exposure. In addition, we wished to provide more complete information on the relative importance of the UVB (280-320 nm), UVA $(320-400 \mathrm{~nm})$, and photosynthetically active radiation (PAR: 400-700 nm) portions of the solar spectrum.

\section{MATERIALS AND METHODS}

All experiments were done in a single outside, flowthrough sea-table at the Shannon Point Marine Center, Anacortes, Washington, USA. The rectangular sea-table 
$(4.0 \mathrm{~m}$ long $\times 0.6 \mathrm{~m}$ wide $\times 0.3 \mathrm{~m}$ deep) received approximately $8 \mathrm{~h}$ of direct sunlight each day. Shields were used to create three light treatments and a dark control in the tank (Table 1). The light treatments added sequential portions of the light spectrum, producing. (1) a PAR treatment; (2) a PAR + UVA treatment; and (3) a PAR + UVA + UVB treatment. All experiments were done in the summer between 16 July and 28 August 1998. The light spectrum was measured in each treatment with a LICOR 1800UW spectroradiometer. Because this instrument only measures wavelengths above $300 \mathrm{~nm}$, we were unable to record the lower UVB wavelengths (i.e. 280-289 nm).

\section{Adult light sensitivity}

To determine whether exposure to natural sunlight damages adult Corella inflata, we collected adults (between 2 and $3 \mathrm{~cm}$ long) from the shaded portions of Skyline Marina in Anacortes, WA and placed three individuals in each light regimen. Because C. inflata are very sensitive to sedimentation and the accumulation of faeces, they could not simply be placed in the bottom of the tank. Instead, a piece of monofilament line was threaded through the tunic at the base of each individual, being careful not to penetrate to the body inside. They were then suspended from a cement block in each section of the tank. This held them horizontally against a vertical surface, $2 \mathrm{~cm}$ below the surface of the water, with the brood chamber up (Child, 1927; Lambert et al., 1995).

The experiment was initially intended to run for several weeks and to measure growth of the C.inflata. However, due to rapid mortality in most treatments, the experiment was ended after only $7 \mathrm{~d}$. The condition of the ascidians was checked daily. Death was indicated when the C. inflata no longer contracted when its siphons were touched. The mean day of death for each treatment was determined. The experiment was repeated three times and the Scheirer-Ray-Hare extension of the KruskalWallis test was used (Sokal \& Rohlf, 1995) to compare the three light treatments and the dark control, the three trials, and the interaction between treatments and trials. This non-parametric analog of a two-way ANOVA was necessary because variances were unequal.

\section{Fuvenile sensitivity}

Juvenile C. inflata were tested to determine whether they were damaged by sunlight exposure, again examining the relative importance of UVB, UVA, and PAR. Juveniles were obtained by collecting adult $C$. inflata from the field, light-shocking them in the laboratory (Lambert et al.,
1981), and collecting fertilized eggs from the atrium. Light-shocking involved exposing newly collected adults to fluorescent lights in the laboratory.

The eggs from ten to 15 adults were mixed and 30 to 50 were placed in each of 16 Petri dishes (depth $=15 \mathrm{~mm}$, diameter $=100 \mathrm{~mm}$ ). The dishes were filled with seawater and held in an incubator at $10^{\circ} \mathrm{C}$ for $3 \mathrm{~d}$. By that time, the eggs had developed into tadpole larvae that had settled in the dishes. The dishes were drained to remove undeveloped eggs and the positions of nine juveniles were marked on the back of the dish with a permanent marker.

Four Petri dishes, each containing nine marked juveniles, were placed in each section of the experimental tank. The dishes were submerged to a depth of $2 \mathrm{~cm}$ directly beneath the shields so they would not be affected by light from other treatments and so the juveniles would be directly flushed by flowing seawater. Seawater temperatures varied slightly from day to day $\left(12.0-13.7^{\circ} \mathrm{C}\right.$ over the period of all experiments), but flow was sufficiently high to prevent the development of temperature differences among the treatments. We recovered the plates after $5 \mathrm{~d}$ and counted the survivors. Data were converted to percentages and analysed by one-way ANOVA. Because the data met all assumptions of analysis of variance, no additional transformations were necessary.

Because light may produce sublethal effects not detected by simple survival counts, the growth of the juveniles was also measured in each treatment. Before the dishes were placed in the outside tank, each was examined with a dissecting microscope and the projected areas of the nine marked juveniles were measured with Optimas image analysis software. At the end of the experiment, the projected areas of each survivor were again measured. Projected area is an imperfect measurement since the juveniles have a third dimension (height). However, preliminary work showed that projected area was a useful index of C. inflata size during early development. To avoid pseudoreplication, the measurements were averaged for all survivors in a single dish. Results were compared with one-way ANOVA.

\section{Sensitivity of embryos and larvae}

To test the sunlight sensitivity of C.inflata embryos, 10-15 adults were spawned and their fertilized eggs collected. The eggs were mixed and placed in plastic Petri dishes ( 200 eggs per dish). Six dishes were placed in each section of the outside tank. The dishes were on cement blocks that lifted their edges just above the surface of the water. This kept the dishes bathed in flowing seawater (to maintain ambient temperature) but prevented the embryos from being flushed out of

Table 1. Materials used to create light treatments used in Corella inflata survival experiments.

\begin{tabular}{lllll}
\hline Shield & Manufacturer & Thickness $(\mathrm{mm})$ & $\begin{array}{l}\text { Wavelengths } \\
\text { transmitted (nm) }\end{array}$ & Treatment \\
\hline Black plastic sheeting & Carlisle Plastics & 0.15 & - & Dark control \\
Plexiglas (UF3) & Atohaas North America & 3.00 & $400-700$ & PAR \\
Mylar & McMaster-Carr & 0.08 & $315-700$ & PAR + UVA \\
Cellulose acetate & McMaster-Carr & 0.13 & $290-700$ & PAR + UVA + UVB \\
\hline
\end{tabular}


the dishes. After $24 \mathrm{~h}$, the dishes were recovered and the embryos examined to determine the percentage that had developed normally. Because the variances could not be homogenized (variance was 0 in some treatments), a Kruskal-Wallace test was used (Sokal \& Rohlf, 1995) to compare the percentage of normally developing embryos in the treatments.

Under normal conditions, the embryos of C.inflata spend their entire developmental period within the brood chamber of the adult; they are not released into the water column as in most other solitary ascidians (Child, 1927; Lambert et al., 1981). It is possible, therefore, that the adult tunic provides some protection for the developing young. This was tested by exposing $C$. inflata embryos to the light treatments while they were still held in the adult brood chamber. Twenty adults were spawned in the early morning, causing them to release their eggs into the brood chamber. Each adult was then gently wedged into a piece of open cell foam in which a slit had been cut. The foam was attached to the inside of a plastic cup that held the adults in their normal position, horizontal with the atrial siphon below the elevated brood chamber.

Each cup was filled, covering the adults with $\sim 2 \mathrm{~cm}$ of seawater. They were then arbitrarily assigned to the dark control and treatment sections of the outside tank (five adults per section). The cups were submerged in flowing seawater that kept temperatures at ambient. After $24 \mathrm{~h}$, the cups were collected and embryos were gently removed from the brood chamber using a pipette. We examined each embryo and determined the percentage that were developing normally. These data were log-transformed to homogenize variances and compared with one-way ANOVA and Tukey's pairwise comparisons (Sokal \& Rohlf, 1995).

To determine the damage threshold of $C$. inflata tadpole larvae, they were exposed to different durations of full sunlight. Twenty adults were spawned and the embryos released were collected. The embryos were placed in a large glass bowl and held in a $12^{\circ} \mathrm{C}$ incubator until they had developed into tadpole larvae $(\sim 20 \mathrm{~h})$. Thirty tadpole larvae were placed in each of 21 Petri dishes. Three of the dishes were immediately placed in the dark section of the experimental tank; the remaining dishes were put in the PAR + UVA + UVB section. At 30-min intervals, three arbitrarily chosen dishes were moved from the exposed to the dark section of the tank until all the dishes had been moved over. Twenty-four hours later, all the inside surfaces of the dish and the water surface were examined to determine the number of larvae that had successfully settled and metamorphosed. The data were converted to percentages and log transformed to linearize the relationship. Results were analysed with a simple linear regression.

\section{RESULTS}

The shields were intended to isolate portions of the sunlight spectrum. The filtering effect was good (Figure 1), but measurements showed that the light distinctions were not absolute. In particular, the mylar shield did not remove all the UVB. The Plexiglas and cellulose acetate shields were more effective at removing their intended

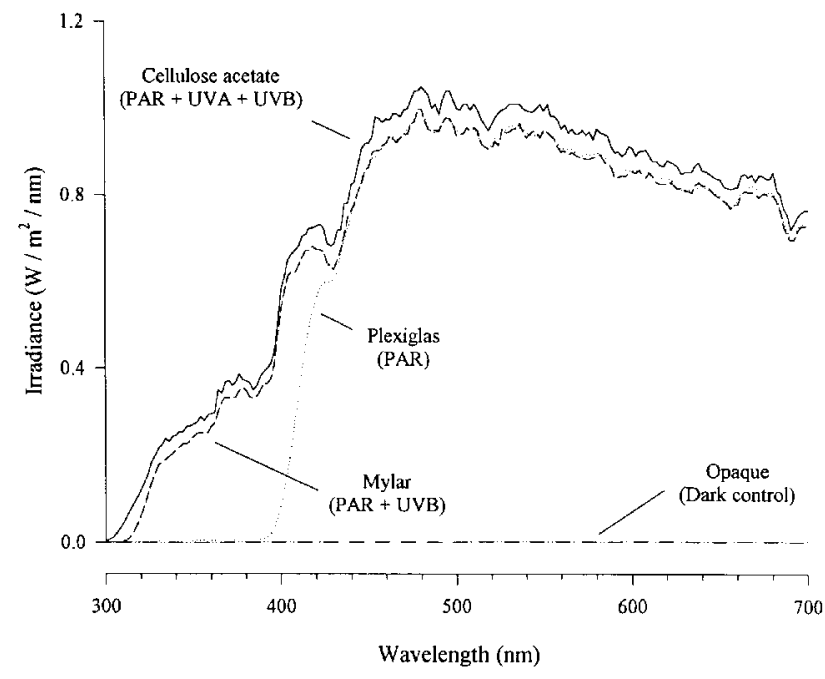

Figure 1. Irradiance spectra of the four treatment sections of the outside experimental tank. Due to instrument constraints, we were unable to measure the UVB portion below $300 \mathrm{~nm}$. Scan was made 24 August 1998 at 1330 hours. Intended treatments are shown in parentheses.

Table 2. Measured light spectra in the experimental tank under natural sunlight. Measurements were made at 1330 hours on 24 August 1998. Per cent transmittance of full spectrum sunlight is shown in parentheses.

\begin{tabular}{lcccl}
\hline Shield & UVB & UVA & PAR & Total light \\
\hline Opaque & 0 & 0 & 0.4 & 0.4 \\
& - & - & $(0.1 \%)$ & $(0.1 \%)$ \\
Plexiglas & 0 & 0.6 & 246.5 & 247.1 \\
& - & $(2 \%)$ & $(88.4 \%)$ & $(81.4 \%)$ \\
Mylar & 0.1 & 22.0 & 252.5 & 274.8 \\
& $(11 \%)$ & $(92.2 \%)$ & $(90.6 \%)$ & $(90.5 \%)$ \\
Cellulose & 1.0 & 24.7 & 267.4 & 293.1 \\
acetate & $(100 \%)$ & $(100 \%)$ & $(95.9 \%)$ & $(96.6 \%)$ \\
No shield & 0.9 & 23.8 & 278.7 & 303.5 \\
\hline
\end{tabular}

wavelengths, but they also reduced the intensity of visible light (Table 2). However, in general, the treatments removed the intended portions of the spectrum and provided realistic measures of the light effects.

\section{Adult survival}

Adult Corella inflata were very sensitive to light. Statistical analysis showed strong differences in survivorship among individuals in the three light treatments and the dark control. There were no differences among the three trials and no interaction between treatments and trials (Table 3). To simplify graphical presentation, the three trials were pooled (Figure 2). The results suggest that any light (including PAR alone) damages adult $C$. inflata. Eighty per cent of the animals exposed to only PAR were dead after $7 \mathrm{~d}$ (compared to $23 \%$ of the dark controls). Surprisingly, the greatest effect did not come from UVB; the addition of UVB did little to reduce survival beyond the effect of UVA alone (all individuals in both groups 
Table 3. Statistical analysis of adult Corella inflata survival under direct sunlight. The analysis was done with a Scheirer-Ray-Hare extension of the Kruskal-Wallis test. Treatments included dark control, PAR, PAR +UVA, and PAR+ $U V A+U V B$. 'Trial' represents three independent experiments.

\begin{tabular}{lrrrl}
\hline Source & df & \multicolumn{1}{l}{ MS } & H & P \\
\hline Treatment & 3 & 2262.26 & 12.66 & 0.005 \\
Trial & 2 & 5.71 & 0.01 & 0.99 \\
Treatment $\times$ Trial & 6 & 62.01 & 0.34 & 0.99 \\
Residual & $\mathbf{3 6}$ & & & \\
Total & 47 & 178.68 & & \\
\hline
\end{tabular}

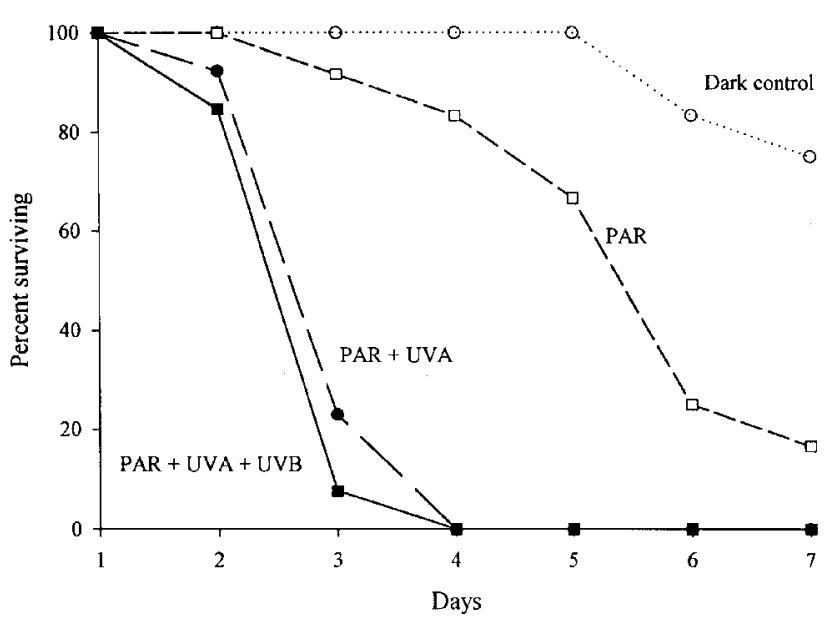

Figure 2. Effects of sunlight on survival of adult Corella inflata. Data are the pooled averages and standard errors for three independent trials $(\mathrm{N}=4$ adults per trial).

were dead after $4 \mathrm{~d}$ ). Individuals in the UV treatments quickly turned opaque and became unresponsive to touch.

\section{Fuvenile survival and growth}

Juvenile C. inflata also responded strongly to sunlight. Exposure to any light again reduced survival (Figure 3). Tukey's pairwise comparisons showed that survival in the three light treatments was lower than in the dark control. The three light treatments were indistinguishable from one another.

Although juveniles in the dark control appeared to have grown more than those exposed to light (Figure 3), no significant differences were found among the treatments. There was great variability in growth among individuals within the groups. In addition, differential mortality made sample sizes unequal $(\mathrm{N}=4$ for dark control and PAR treatments, $\mathrm{N}=3$ for the PAR + UVA treatment, $\mathrm{N}=2$ for the PAR + UVA + UVB treatment). The small sample sizes resulted in a power estimate of only 0.16 indicating that there was little chance of detecting treatment differences given the high variability in growth and the small effect size. Clearly, it would have been desirable to have larger, equal sample sizes.

\section{Sensitivity of embryos and larvae}

Light had a strong impact on development of C. inflata embryos that had been extracted from the adult brood
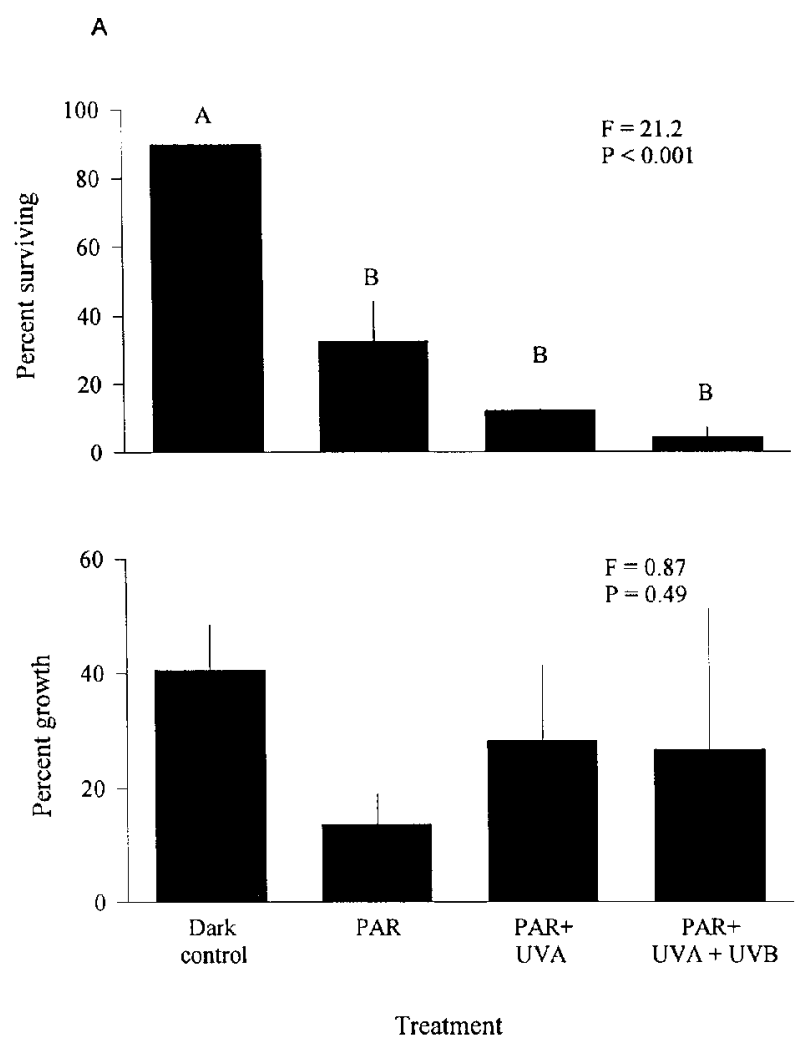

Figure 3. Effects of light on survival and growth of juvenile Corella inflata. Data were collected after $5 \mathrm{~d}$ of exposure to natural sunlight. Standard errors are shown. Letters over the bars represent the results of Tukey's pairwise comparisons (treatments with the same letter were not statistically different).

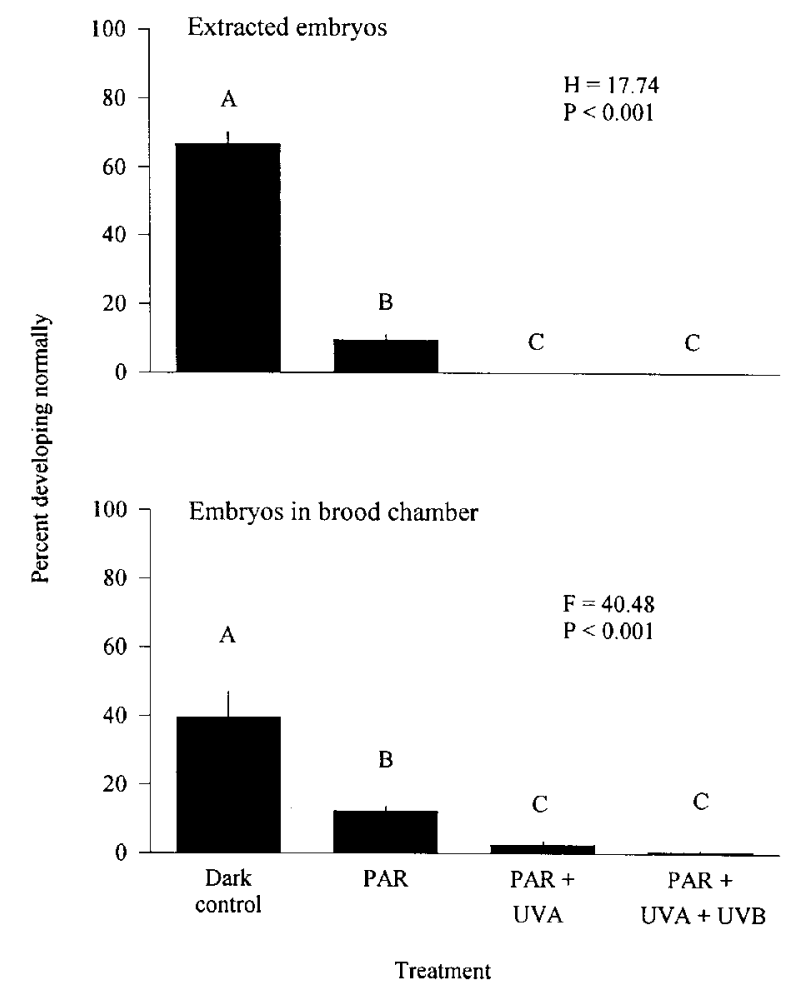

Figure 4. Effects of light exposure on embryonic development of Corella inflata: (1) extracted from the adult brood chamber; and (2) held in the brood chamber. Letters indicate means that were not significantly different by Tukey's pairwise comparisons. Standard errors are shown. 


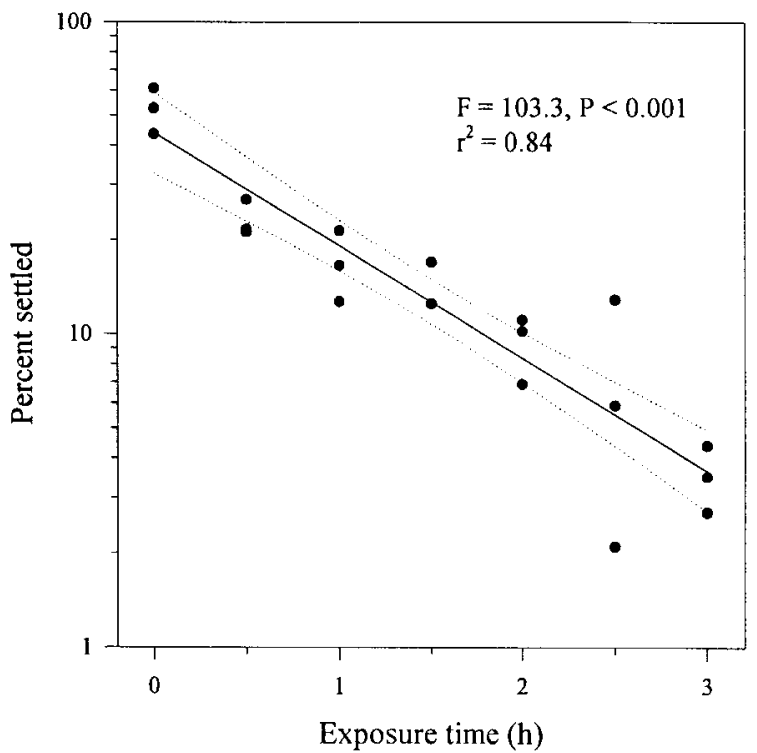

Figure 5. Cumulative effects of sunlight exposure on Corella inflata larval settlement. Exposures ranged from 0 to $3 \mathrm{~h}$ in 30 -min intervals. A simple linear regression with a $95 \%$ confidence interval and regression statistics is shown. Note the logarithmic y-axis.

chamber (Figure 4). No normal development occurred when the embryos were exposed to any UV light; PAR also significantly decreased the percentage of embryos that developed normally. A comparison of the mean ranks showed that significantly more normal development occurred in the dark control.

Being held within the adult brood chamber provided some limited protection to the developing embryos (Figure 4) with a very small number of embryos developing normally even in the UV treatments. However, the light damage was still severe. Significantly more abnormal embryos were produced in both UV treatments. Visible light alone again caused a significant decrease in the proportion of normal embryos.

Any exposure to full-spectrum sunlight significantly decreased settlement of the $C$. inflata tadpole larvae. The effect was very strong after only $30 \mathrm{~min}$; settlement dropped approximately $15 \%$. Settlement success continued to decrease as exposure time increased. Only $3-4 \%$ of the tadpoles successfully settled after $3 \mathrm{~h}$ of sunlight exposure.

\section{DISCUSSION}

Corella inflata were remarkably vulnerable to sunlight damage. Adults, juveniles, larvae, and embryos were all killed after very short exposures. It has long been known that the high-energy UVB radiation in sunlight can damage living organisms. In the present study, UVB was certainly responsible for some of the observed $C$. inflata mortality. However, the damage was much greater than would be expected from UVB exposure alone.

Bingham \& Reyns (1999) exposed C. inflata to artificial laboratory UVB under a 15:9 light:dark cycle. Although the UVB intensity in that study was similar to the maximum measured in the present work (approximately $1.1 \mathrm{~W} \mathrm{~m}^{-2}$ ), the cumulative UVB exposure was much higher. The Bingham \& Reyns (1999) UV intensity was $\sim 1.1 \mathrm{~W} \mathrm{~m}^{-2}$ for the full $15 \mathrm{~h}$ of exposure; there were no decreases at dusk or dawn and no correction for cloud cover, solar angle, or shading. In fact, we estimate that the total UVB exposures in Bingham \& Reyns (1999) were 4-5 times higher than ambient.

Despite our much lower natural UVB exposure, greater damage to adult and larval C. inflata was observed. Adults survived nearly $14 \mathrm{~d}$ of laboratory UVB exposure in the study of Bingham \& Reyns (1999), but lasted only $2 \mathrm{~d}$ in natural sunlight. Similarly, a 30-min laboratory UVB exposure decreased C.inflata larval settlement approximately $5 \%$. The same exposure to natural sunlight produced a $15 \%$ drop (Figure 5).

The differences in results of these two studies can be attributed to the effects of UVA and PAR. While the artificial lights used by Bingham \& Reyns (1999) exaggerated UVB nearly $500 \%$, their UVA and PAR intensities were approximately $3000 \%$ below ambient. UVA is often considered beneficial; laboratory studies suggest that UVA irradiation reverses the DNA damage caused by UVB (Holm-Hansen et al., 1993; Mitchell \& Karentz, 1993; Quesada et al., 1995). However, it can also have strong negative effects (Urbach \& Gange, 1986). UVA kills bacteria (Sieracki \& Sieburth, 1986), protozoans (Sommaruga et al., 1996) and phytoplankton (Doehler et al., 1997). It may also interfere with the settlement of coral larvae (Baker, 1995).

Our results suggest that natural UVA significantly damages adults and embryos of C.inflata. Addition of UVA wavelengths caused adult survival to drop an additional 50\% compared to PAR alone (Figure 2). UVA also had a major impact on development whether embryos were completely exposed or held within the adult brood chamber; survival was near zero in both cases (Figure 4).

It was surprising to discover that visible light (PAR) also had an apparent effect on all life stages of $C$. inflata. This was particularly evident in the juvenile and larval experiments (Figures $3 \& 4$ ) where the greatest drop in survival came, not with the addition of UVA or UVB, but with the addition of visible light alone. Visible light itself has rarely been identified as a cause of mortality for marine invertebrates, but PAR does damage cyanobacteria (Miller et al., 1998), Escherichia coli (Gourmelon et al., 1994) and in vitro mammalian cells (Pflaum et al., 1998), possibly through the production of free oxygen radicals. PAR may also contribute to bleaching and mortality of corals (Brown et al., 1994; Lewis, 1995).

Given the vulnerability of $C$. inflata to sunlight damage, it might be expected to have special adaptations to deal with this strong selective force. This does not seem to be the case. Adults are sessile and cannot move from the site the larva has chosen for settlement. Nor can the adults shield their developing embryos and brooded larvae from the damaging effects of sunlight. Furthermore, the embryos seem to lack the UV-absorbing sunscreens that protect the developing embryos of the ascidian Ascidia ceratodes (Epel et al., 1999).

In its natural habitats, C. inflata is largely restricted to deeper subtidal waters (Young, 1982) or to the shaded surfaces of docks, floats, and other artificial structures. 
They rarely occur in intertidal or shallow subtidal water where they would be exposed to sunlight (UVA can penetrate to at least $14 \mathrm{~m}$ in the local waters; Bingham \& Reyns, 1999). The interaction of light intensity and duration of exposure may set a threshold that limits horizontal (shaded vs unshaded) and vertical (shallow vs deep) distribution. Our exposures in the outdoor tank modelled an extreme case with animals fully exposed to summer sunlight in shallow water. In any habitat, natural conditions of daylength, cloud cover, solar angle, water turbidity, substratum reflectivity and depth are likely to contribute to more complex smaller-scale C. inflata distributions.

Bingham \& Reyns (1999) suggest that the time of spawning of $C$. inflata, its period of development, brooding behaviour, and short free-swimming larval period combine to keep populations concentrated near established adults (in protected locations). Such a larval settlement pattern was described by Lambert (1968). Larvae that settle in exposed sites probably die quickly. The distributional patterns observed, therefore, are likely a result of both larval settlement patterns and early postsettlement mortality.

There is currently much concern over the status of the stratospheric ozone layer and the effects of UVB on plants and animals. While C.inflata populations may be somewhat affected by UVB and could be impacted by increasing UVB intensity, it appears that their basic ecology is more influenced by PAR and UVA (neither of which is expected to increase with ozone depletion; Madronich, 1993). More information on the damage thresholds and the mechanisms of damage will help us better understand the ecology of this unique organism.

We gratefully acknowledge the technical assistance of Gene McKeen and Mike Strom. Deneb Karentz, Charles Lambert and Gretchen Lambert provided valuable information and reviewed an early draft of the manuscript. Steve Sulkin made laboratory space available at the Shannon Point Marine Center. This work was supported by NSF grants OCE-9340328 and USE-9151453 and a summer research grant from Western Washington University.

\section{REFERENCES}

Baker, A.C., 1995. Solar UV-A inhibition of planula larvae in the reef-building coral Pocillopora damicornis. Ultraviolet Radiation and Coral Reefs, Dec, 149-163.

Bingham, B.L. \& Reyns, N.B., 1999. Ultraviolet radiation and distribution of the solitary ascidian, Corella inflata (Huntsman). Biological Bulletin. Marine Biological Laboratory, Woods Hole, 196, 94-104.

Björn, L.O. \& Teramura, A.H., 1993. Simulation of daylight ultraviolet radiation and effects of ozone depletion. In Environmental UV photobiology (ed. A.R. Young et al.), pp. 41-71. New York: Plenum Press.

Bornman, J.F. \& Teramura, A.H., 1993. Effects of ultraviolet-B radiation on terrestrial plants. In Environmental UV photobiology (ed. A.R. Young et al.), pp. 427-471. New York: Plenum Press.

Brown, B.E., Dunne, R.P., Scoffin, T.P. \& Le Tissier, M.D.A., 1994. Solar damage in intertidal corals. Marine Ecology Progress Series, 105, 219-230.

Buma, A.G.J., Van Hannen, E.J., Roza, L. \& Veldhuis, M.J.W., 1995. Monitoring ultraviolet-B-induced DNA damage in individual diatom cells by immunofluorescent thymine dimer detection. Fournal of Phycology, 31, 314-321.
Child, G.M., 1927. Developmental modification of the larval stage in the ascidian Corella willmeriana. Fournal of Morphology, 44, 467-517.

Dey, D.B., Damkaer, D.M. \& Heron, G.A., 1988. UV-B dose/ dose-rate responses of seasonally abundant copepods of Puget Sound. Oecologia, 76, 321-329.

Dionisio-Sese, M.L., Ishikura, M., Maruyama, T. \& Miyachi, S., 1997. UV-absorbing substances in the tunic of a colonial ascidian protect its symbiont, Prochloron sp., from damage by UV-B radiation. Marine Biology, 128, 455-461.

Dohler, G., Drebes, G. \& Lohmann, M., 1997. Effect of UV-A and UV-B radiation on pigments, free amino acids and adenylate content of Dunaliella tertiolecta Butcher (Chlorophyta). Fournal of Photochemistry and Photobiology B, 40, 126-131.

Epel, D., Hemela, K., Schick, M. \& Patton, C., 1999. Development in the floating world: defenses of eggs and embryos against damage from UV radiation. American Zoologist, 39, 271-278.

Gourmelon, M., Cillard, J. \& Pommepuy, M., 1994. Visible light damage to Escherichia coli in seawater: oxidative stress hypothesis. Fournal of Applied Bacteriology, 77, 105-112.

Holm-Hansen, O., Lubin, D. \& Helbling, E.W., 1993. Ultraviolet radiation and its effects on organisms in aquatic environments. In Environmental UV photobiology (ed. A.R. Young et al.), pp. 379-425. New York: Plenum Press.

Jokiel, P.L., 1980. Solar ultraviolet radiation and coral reef epifauna. Science, New York, 207, 1069-1071.

Karentz, D., 1994. Ultraviolet tolerance mechanisms in Antarctic marine organisms. Antartic Research Series, 62, 93110.

Karentz, D. et al., 1994. Impact of UV-B radiation on pelagic freshwater ecosystems: report of working group on bacteria and phytoplankton. Archiv für Hydrobiologie Beihefte, 43, 31-69.

Karentz, D., McEuen, F.S., Land, M.C. \& Dunlap, W.C., 1991. Survey of mycosporine-like amino acid compound in Antarctic marine organisms: potential protection from ultraviolet exposure. Marine Biology, 108, 157-166.

Kobayashi, J., Nakamura, H. \& Hirata, Y., 1981. Isolation and structure of a UV-absorbing substance 337 from the ascidian Halocynthia roretzi. Tetrahedron Letters, 22, 3001-3002.

Lambert, G.C., Lambert, I.M. \& Lambert, G., 1995. Brooding strategies in solitary ascidians: Corella species from north and south temperate waters. Canadian Fournal of Zoology, 73, 16661671.

Lambert, G., 1968. The general ecology and growth of a solitary ascidian, Corella willmeriana. Biological Bulletin. Marine Biological Laboratory, Woods Hole, 135, 296-307.

Lambert, G., Lambert, C.C. \& Abbott, D.P., 1981. Corella species in the American Pacific Northwest: distinction of C. inflata Huntsman, 1912 from C.willmeriana Herdman, 1898 (Ascidiacea, Phlebobranchia). Canadian Fournal of Zoology, 59, 1493-1504.

Lewis, S., 1995. Response of a Pacific stony coral to short-term exposure of ultraviolet and visible light. Ultraviolet Radiation and Coral Reefs, Dec, 89-106.

Madronich, S., 1993. Tropospheric photochemistry and its response to UV changes. In The role of the stratosphere in global change, vol. 18 (ed. M.L. Chanin), pp. 437-461. Amsterdam: Springer-Verlag.

Miller, S.R., Wingard, C.E. \& Castenholz, R.W., 1998. Effects of visible light and UV radiation on photosynthesis in a population of a hot spring cyanobacterium, a Synechococcus sp., subjected to high-temperature stress. Applied and Environmental Microbiology, 64, 3893-3899.

Mitchell, D.L. \& Karentz, D., 1993. The induction and repair of DNA photodamage in the environment. In Environmental $U V$ photobiology (ed. A.R. Young et al.), pp. 345-377. New York: Plenum Press. 
Pflaum, M., Kielbassa, C., Garmyn, M. \& Epe, B., 1998. Oxidative DNA damage induced by visible light in mammalian cells: extent, inhibition by antioxidants and genotoxic effects. Mutation Research, 408, 137-146.

Quesada, A., Mouget, J.-L. \& Vincent, W.F., 1995. Growth of Antarctic cyanobacteria under ultraviolet radiation: UVA counteracts UVB inhibition. Fournal of Phycology, 31, 242-248.

Sieracki, M.E. \& Sieburth, J.M., 1986. Sunlight-induced growth delay of planktonic marine bacteria in filtered seawater. Marine Ecology Progress Series, 33, 19-27.

Sokal, R.R. \& Rohlf, F.J., 1995. Biometry. The principles and practices of statistics in biological research, 3rd ed. New York: W.H. Freeman \& Co.

Sommaruga, R., Oberleiter, A. \& Psenner, R., 1996. Effect of UV radiation on the bacterivory of a heterotrophic nanoflagellate. Applied and Environmental Microbiology, 62, 4395-4400.
Urbach, F. \& Gange, R.W., ed., 1986. The biological effects of UVA radiation. New York: Praeger Publishers.

Williamson, C.E., 1996. Effects of UV radiation on freshwater ecosystems. International Fournal of Environmental Studies $A \& B$, 51, 245-256.

Young, G.M., 1982. Larval behavior, predation, and early post-settlement mortality as determinants of spatial distribution in subtidal solitary ascidians of the San Fuan Islands, Washington. $\mathrm{PhD}$ thesis, University of Alberta, Edmonton, Alberta, Canada.

Zellmer, I.D., 1998. The effect of solar UVA and UVB on subarctic Daphnia pulicaria in its natural habitat. Hydrobiologia, $379,55-62$.

Submitted 12 November 1999. Accepted 22 February 2000. 